\title{
Risk of Strong Hurricane Winds to Florida Cities
}

\author{
Jill C. Malmstadt, James B. Elsner, and Thomas H. Jagger \\ The Florida State University, Tallahassee, Florida
}

(Manuscript received 19 October 2009, in final form 17 May 2010)

\begin{abstract}
A statistical procedure for estimating the risk of strong winds from hurricanes is demonstrated and applied to several major cities in Florida. The procedure, called the hurricane risk calculator, provides an estimate of wind risk over different length periods and can be applied to any location experiencing this hazard. Results show that the city of Miami can expect to see hurricane winds blowing at $50 \mathrm{~m} \mathrm{~s}^{-1}\left[45.5-54.5 \mathrm{~m} \mathrm{~s}^{-1}\right.$ is the $90 \%$ confidence interval (CI)] or stronger, on average, once every $12 \mathrm{yr}$. In comparison, the city of Pensacola can expect to see hurricane winds of $50 \mathrm{~m} \mathrm{~s}^{-1}\left(46.9-53.1 \mathrm{~m} \mathrm{~s}^{-1}, 90 \% \mathrm{CI}\right)$ or stronger once every $24 \mathrm{yr}$. A quantile regression is applied to hurricane wind speeds in the vicinity of Florida. Results show that the strongest hurricanes are getting stronger as a consequence of higher offshore intensification rates.
\end{abstract}

\section{Introduction}

Every year hurricanes threaten the United States with the potential for catastrophic losses of life and property. The risk of a catastrophe varies by location. The state of Florida is particularly vulnerable due to its position surrounded by warm seas. According to Blake et al. (2007), $40 \%$ of all U.S. hurricanes and major hurricanes hit Florida; and $83 \%$ of category 4 or higher hurricane strikes have hit either Florida or Texas. Due to increasing populations and economic development in the areas prone to devastation, average economic losses are increasing over time (Malmstadt et al. 2009). For society to better cope with and mitigate these disasters, a more precise estimate of the risk of high winds on the local level is needed. Indeed, companies can use this kind of information to sell catastrophe bonds that break down potential hurricane wind losses by municipality.

Here, we consider wind risk from a hurricane as the probability of a region experiencing winds of hurricane force or greater within a specified period. Within this context, risk is an attribute of a region that is determined by the size and location of the region and not by the potential for loss of life or property. Risk is an unobserved and changing quantity that is estimated using a statistical procedure. The procedure provides an estimate

Corresponding author address: Jill C. Malmstadt, Dept. of Geography, The Florida State University, Tallahassee, FL 32306. E-mail: jmalmstadt@fsu.edu of the exceedence wind speed (return level) as a function of the return period (inverse of the annual probability). The primary goal here is to quantify the level of risk of hurricane winds of varying magnitudes blowing over a particular region over a given time period. This method can provide useful return-level estimates for homeowners on a 20-30-yr mortgage as well as provide information at similar time scales as offered for the $100-y r$ flood plain in the hydrology literature (Bin et al. 2008).

In particular, the present work estimates return levels of hurricane winds affecting Florida cities and examines the case for secular trends in the intensity and frequency of hurricanes in the vicinity of the state. This is an application of the Elsner et al. (2008a) model, where information from past cyclones affecting the city and its vicinity are combined through the parameters of an extreme-value distribution to estimate return levels. This paper goes beyond the initial work by automating the procedure and applying it to cities in Florida. This procedure, called the hurricane risk calculator (HRC), borrows information from a larger region to estimate the distribution parameters for a smaller region. The methodology implicitly assumes a stationary climate with regard to the occurrence and intensity of the wind events. Here, we shed some light on this assumption by examining the case for trends in hurricane activity in and around the state of Florida using the method of quantile regression as introduced in the study of hurricane climatology in Elsner et al. (2008b). 
The paper begins with a description of the data used for this study in section 2. Section 3 discusses the statistical procedure for estimating local wind risk. Section 4 gives the results of the return-period calculations for selected Florida cities. Section 5 presents the methods and results of the trend analysis of hurricanes in the vicinity of Florida. Section 6 summarizes the results and emphasizes the important conclusions of this study. The work is important in providing reliable estimates of hurricane wind return periods for the population centers of Florida and for demonstrating a statistically significant trend in hurricane intensification rates in the vicinity of the state.

\section{Hurricane data}

For this study, the wind speed estimates used in the HRC are derived from the National Hurricane Center's Hurricane Database (HURDAT, or best track; see Landsea et al. 2004). This is the official record of tropical cyclones for the Atlantic Ocean, Gulf of Mexico, and Caribbean Sea, including those that have made a U.S. landfall. This record consists of the 6-hourly cyclone location and intensity for individual storms back to 1851 . For cyclones prior to 1931, the 6-h information is interpolated from once-daily (1200 UTC) estimates. For cyclones in the period 1931-56, the 6-h information is interpolated from twice-daily observations (0000 and 1200 UTC). Analyses were previously conducted on storms during the second half of the nineteenth and early twentieth centuries to improve the quality of the data (Fernandez-Partagas and Diaz 1996; Landsea et al. 2004).

There remain limitations to these data that are relevant to the present study. Storm information over the earlier part of the record is less certain than information over the more recent decades (Landsea et al. 2004). This time variation in uncertainty is likely larger in the collection of tropical cyclones occurring over the open ocean, but presents itself to some degree in land-falling hurricanes. Unless the area was at least sparsely populated at the time of landfall, the hurricane wind speed may not have been recorded. Despite the limitations, these data are frequently used for hurricane risk analysis (Emanuel et al. 2006). Our approach is to show results from the HRC using all the data and then compare these results with results from the procedure using the shorter more reliable set of years.

The hurricane data were interpolated hourly for the geographic position of the hurricane center (center fix) and wind speed using splines described in Jagger and Elsner (2006). Splines are parsimonious smooth representations of the data that preserve local properties. Figure 1 shows hurricane intensity as a function of storm hour using the raw and 1-hourly spline interpolated values

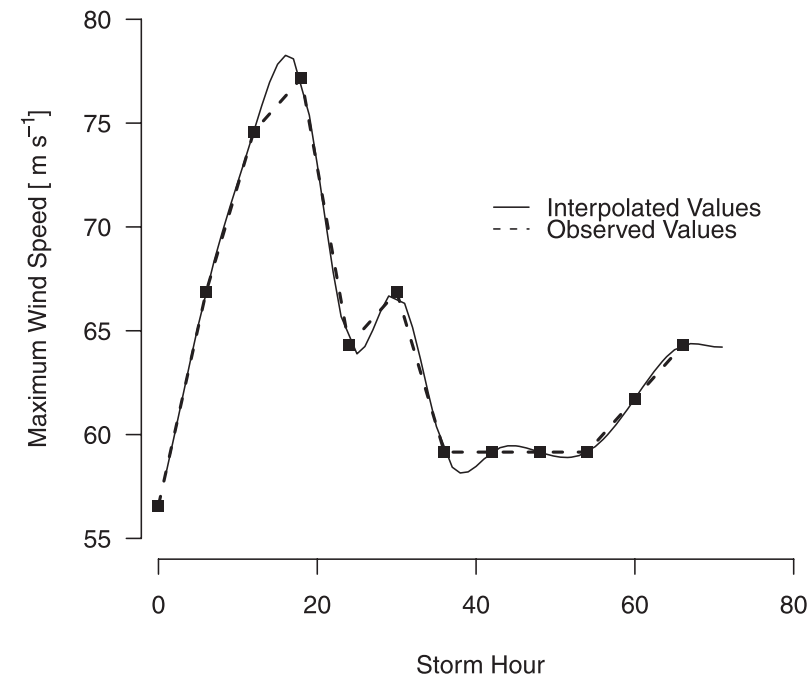

FIG. 1. Interpolated wind values. Hurricane wind intensity $\left(\mathrm{m} \mathrm{s}^{-1}\right)$ is plotted as a function of storm hour for Hurricane Andrew (1992). The first observation of the storm is the 0 storm hour. The boldface line and accompanying points show the 6-hourly observed wind speeds (maximum sustained) as taken directly from HURDAT. The smooth line shows the hourly spline interpolation used in this work and as derived in Jagger and Elsner (2006).

for one case. We see that the spline smoothing preserves the 6-hourly wind speed and gives a nonlinear interpolation of values at each hour between these values. The advantage of the hourly interpolated values is that the chance of missing a hurricane passing through any given area is greatly reduced. For example, with the 6-hourly data and an average translational velocity of $18 \mathrm{~km} \mathrm{~h}^{-1}$, we would expect to miss about $10 \%$ of all hurricanes crossing a circular region with a radius of $75 \mathrm{~km}$ (smallest search radius used in this study). In contrast, we would expect to miss only about $0.2 \%$ of the hurricanes ( 2 in 1000 storms) crossing through the same region using hourly data. The missing track proportion is calculated assuming uniform track density and a fixed wind speed.

As noted in Neumann (1987), estimated return levels assume that the hurricane climatology over the past $158 \mathrm{yr}$ will remain unchanged. Also, for this study, the occurrence of a hurricane within the city is independent of future hurricanes within the same city. This latter assumption is reasonable, but as we explore in section 5 of this paper there is some evidence that Florida's hurricane climate is changing. We begin by looking at the procedure for estimating return levels locally.

\section{Methodology}

The climatological probability of hurricane winds can be estimated in various ways. Heckert et al. (1998) use the peaks-over-threshold model and a reverse Weibull 
distribution to obtain the mean recurrence intervals for extreme wind speeds at various locations along the U.S. coastline. Chu and Wang (1998) use extreme value distributions to model return periods for tropical cyclone wind speeds in the vicinity of Hawaii. Jagger et al. (2001) use a maximum likelihood estimator to determine a linear regression for the parameters of the Weibull distribution for tropical cyclone wind speeds in coastal counties of the United States.

Jagger and Elsner (2006) produce estimates for extreme hurricane winds near the United States using a generalized Pareto distribution (GPD). The approach includes covariate information to adjust the return levels depending on climate factors, like the El Niño and the North Atlantic Oscillation. The approach is modified in Elsner et al. (2008a) to estimate hurricane return levels for Lake Shelby, Alabama, as a way of comparing geological proxies of past hurricanes with historical records. Parisi and Lund (2008) use a similar approach but add a component for the day of hurricane occurrence.

Here, we automate the approach of Elsner et al. (2008a) to estimate local return levels for 12 cities in Florida and we call it the HRC. Specifically, the distribution of the maximum wind above a threshold value $u$ is assumed to follow a GPD. The threshold value for the extreme value model is determined using the mean residual life plot (Davison and Smith 1990). This plot is produced by averaging the difference in the observed wind speeds above a specified level as a function of the level. For example, at a wind speed level of $30 \mathrm{~m} \mathrm{~s}^{-1}$, we subtract 30 from each observed wind speed and average only the positive values (excesses). This is repeated for all wind speed levels. The mean excess is the expected value of the amount by which the observations exceed the particular level. In other words, if extreme values follow a GPD, then the expected value of the excesses is a linear function of the threshold.

Following Jagger and Elsner (2006), the exceedences $W-u$ are modeled as samples from a family of GPDs, so that for an individual hurricane with maximum wind $W$,

$$
\begin{aligned}
\operatorname{Pr}(W>v \mid W>u) & =\left[1+\frac{\xi}{\sigma}(v-u)\right]^{-1 / \xi} \\
& =\operatorname{GPD}(v-u \mid \sigma, \xi)
\end{aligned}
$$

where $\sigma>0$ and $\sigma+\xi(v-u) \geq 0$. For negative values of the shape parameter $(\xi)$, the GPD family of distributions has an upper limit of $W_{\max }=u+\sigma_{u} /|\xi|$.

The frequency of storms with intensity of at least $u$ follows a Poisson distribution with a rate $\lambda_{u}$, which is the threshold crossing rate. Thus, the number of hurricanes per year with winds exceeding $v$ is a thinned Poisson process with mean $\lambda_{v}=\lambda_{u} \operatorname{Pr}(W>v \mid W>u)$. This is called the peaks-over-threshold (POT) method, and the resulting model is completely characterized for a given threshold $u$ by $\sigma, \xi$, and $\lambda_{u}$, which are the GPD parameters and the threshold crossing rate, respectively.

Since the number of storms exceeding any wind speed $v$ is a Poisson process, the return period for any $v$ has an exponential distribution, with mean $r(v)=1 / \lambda_{v}$. By substituting for $\lambda_{v}$ in terms of both $\lambda_{u}$ and the GPD parameters, then solving for $v$ as a function of $r$, we can find the corresponding return level for a given return period as

$$
\mathrm{rl}(r)=u+\frac{\sigma}{\xi}\left[\left(r \times \lambda_{u}\right)^{\xi}-1\right]
$$

For a more complete description of the statistical theory supporting this model, please refer to Coles (2001), and for an example of the application of POT to maximum wind speeds in hurricanes, refer to Jagger and Elsner (2006).

This model estimates how long on average an area can expect to wait to experience a hurricane of a given intensity. Unfortunately for most small areas like cities, there are too few historical hurricanes to provide a stable estimate of the model parameters. Therefore, the parameters at the smaller radial distance are extrapolated using linear regression from multiple correlated sets of parameters taken at larger radial distances surrounding the location. An example of how this is done in the HRC is provided in the next section.

\section{Results}

The locations of the 12 cities used in this study were obtained from the U.S. Geological Survey's database (which is available online at http://geonames.usgs.gov) and describe the geographic center of the city limits as recognized by the federal government. Each city is chosen based on its level of population density, as well as its potential risk for hurricane damage. Twelve cities were chosen to map out the spatial differences for locations from the western panhandle to the northeast coast of the state (Fig. 2).

The city center is considered the geographic center of the city limits as defined by the federal government. A $100-\mathrm{km}$ radial circle is drawn around each center. The 2000 U.S. Census information is used to show Florida's county population per square kilometer.

The HRC procedure is outlined here for Miami. Figure 3 shows the GPD model parameters and their $90 \%$ confidence intervals for increasing radial distances from the geographic center of the city from 75 to $200 \mathrm{~km}$ at increments of $25 \mathrm{~km}$. Each parameter is estimated based 


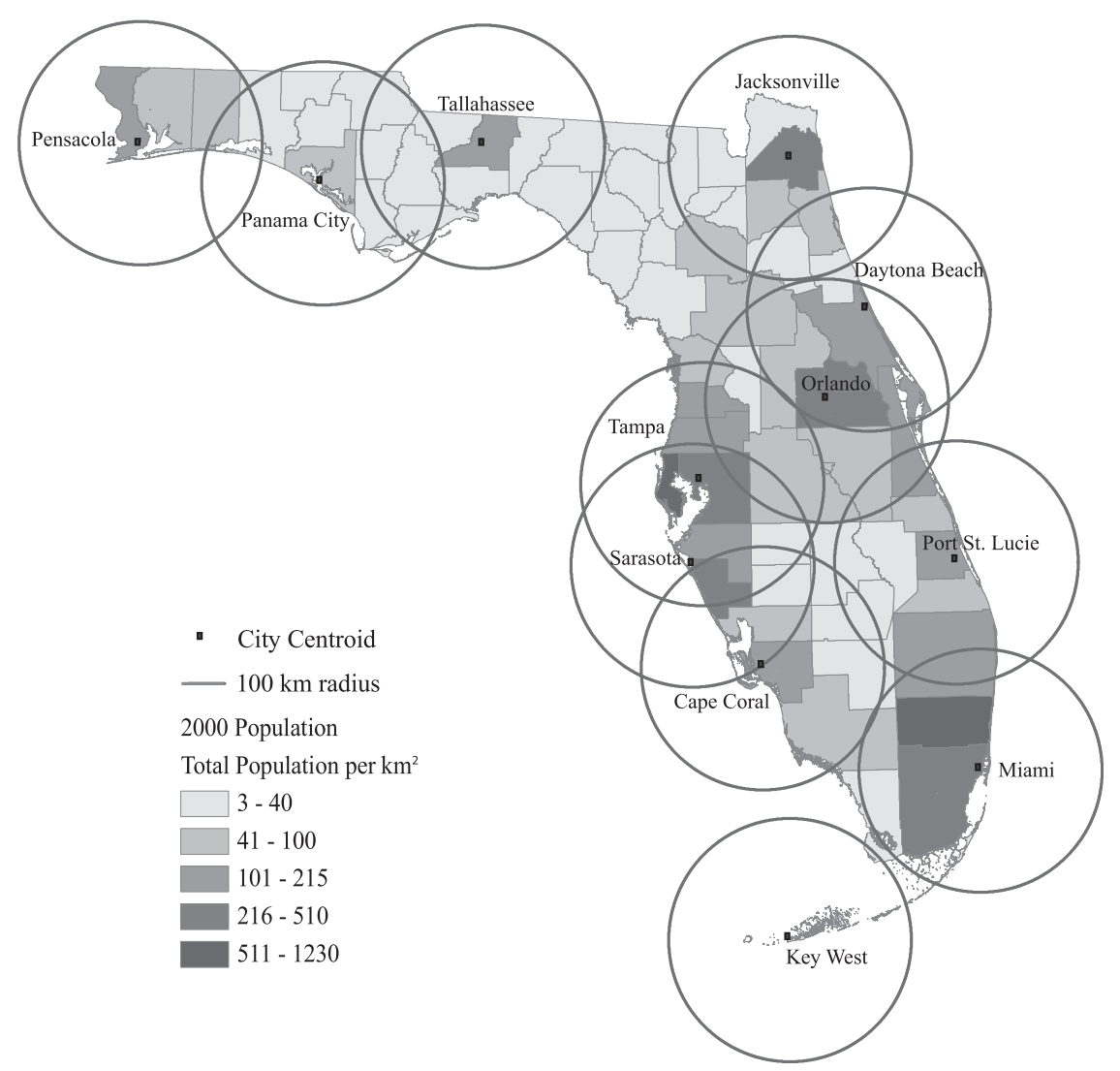

FIG. 2. The 12 FL cities used in this study are shown with the city centroid location denoted with a square. The $100-\mathrm{km}$ radial distance from the city center is shown with a circle. This distance is used in the HRC and encompasses each city. County shading represents the population density per square kilometer.

on the statistical procedure described in the previous section and plotted as a function of radius from the city center. A confidence interval (CI) about the mean return level is obtained by scaling the CI obtained from using a larger radial distance (see Elsner et al. 2008a). This is done by, first, calculating the return levels for a given return period and, then, by assuming the estimate is asymptotically normal from a knowledge of the limiting variance of the estimator (delta method). Note that for radii larger than $125 \mathrm{~km}$ the change in parameter values is linear. We exploit this linear relationship and determine a separate bivariate regression for each parameter as a function of the search radius between 125 and $200 \mathrm{~km}$. The regression line (solid) is used to extrapolate the parameter value at the radial distance of $100 \mathrm{~km}$ for each parameter (point indicated on the regression line). Thus, parameters at the small radial distance of interest are extrapolated using the parameters at larger radial distances.

The threshold $u$ used in the model varies for each location depending on the mean residual life plot produced. The choice is a compromise between having wind speeds high enough for a proper GPD fit but enough of them that the parameter estimates of the GPD are reliable. The thresholds range from 20 to $35 \mathrm{~m} \mathrm{~s}^{-1}$. With a proper threshold, the values of $\xi$ are greater than -1 and the change as a function of radius is small. Figure 4 shows the $\xi$ parameter from Miami's estimates as an example. The dotted line shows the $\xi$ parameter using a threshold that is too high for the model $\left(40 \mathrm{~m} \mathrm{~s}^{-1}\right)$ and the solid line shows $\xi$ using a threshold that is appropriate for the model $\left(35 \mathrm{~m} \mathrm{~s}^{-1}\right)$. Although the choice of the precise threshold is somewhat arbitrary, for each location we check to see that the choice made is not overly sensitive to the search radius.

The return-level curve for Miami using data from 1851 and parameters extrapolated to a radius of $100 \mathrm{~km}$ is shown in Fig. 5. The return period in years is shown along the horizontal axis with a log scale. The return level indicating wind speeds $\left(\mathrm{m} \mathrm{s}^{-1}\right)$ is shown along the vertical axis with a linear scale. The $90 \%$ uncertainty range on the return levels is shown with vertical lines. The model curve indicates that Miami (within a $100-\mathrm{km}$ radius from the city center) can expect a hurricane of at least 

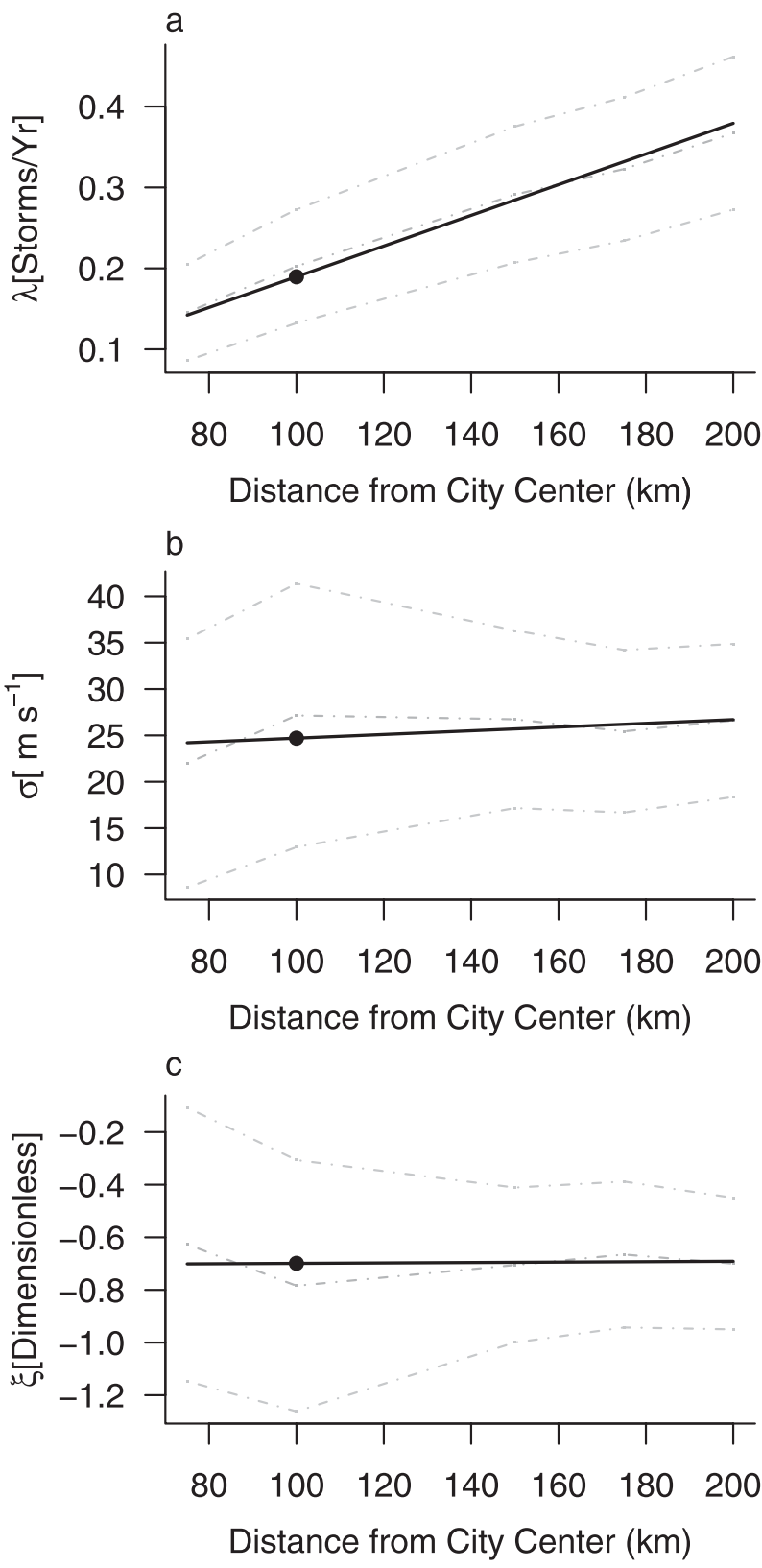

FIG. 3. Values for the HRC parameters $(\lambda, \sigma$, and $\xi)$ as a function of radial distance. Parameter values are obtained from a maximum likelihood procedure using the fastest wind speeds from hurricanes occurring within a radial distance of the geographic center of $\mathrm{Mi}$ ami. The thick solid line indicates the regression line of the parameter vs distance from the city center.

$33 \mathrm{~m} \mathrm{~s}^{-1}$, with a $90 \%$ uncertainty of $\left(26.9-39.1 \mathrm{~m} \mathrm{~s}^{-1}\right)$ on average once every $5 \mathrm{yr}$ and a hurricane of at least $50 \mathrm{~m} \mathrm{~s}^{-1}\left(45.5-54.5 \mathrm{~m} \mathrm{~s}^{-1}\right)$ on average once every $12 \mathrm{yr}$. Since the estimate is over an area and wind speeds diminish rapidly as the hurricane moves over land, it most accurately represents the portion of the area over (or nearest) the ocean. For comparison, we reran the model

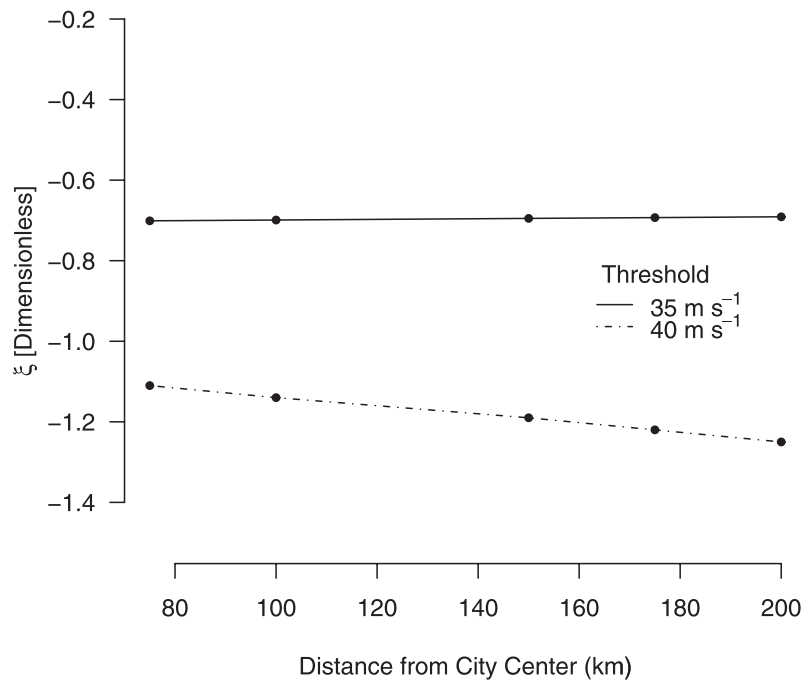

FIG. 4. Miami's $\xi$ threshold parameter as a function of radial distance. The dotted line shows the parameter using a $40 \mathrm{~m} \mathrm{~s}^{-1}$ threshold. The solid line shows the parameter using a $35 \mathrm{~m} \mathrm{~s}^{-1}$ threshold.

using hurricanes limited to the period 1899-2008. The return-level curve is similar (dashed line). The estimates using data from 1899 produce higher return levels for return periods in the range from about 5 to 100 yr. However, the estimates fall within the $90 \%$ confidence level produced by using data from 1851 .

The HRC is repeated for the other 11 cities. Table 1 displays the number of hurricanes passing through each city over the period $1851-2008$, inclusive. The pass through is defined by the center fix passing within a $100-\mathrm{km}$ great-circle distance of the geographical center of the city. The hurricane wind speeds are broken into the five Saffir-Simpson categories and show the variations between locations. Each city is threatened by hurricane winds and all have experienced at least category 3 winds (50-58 $\left.\mathrm{m} \mathrm{s}^{-1}\right)$, except Tallahassee. Pensacola has experienced the most category 1 hurricanes. Overall, Miami has experienced the most hurricanes, with 35 strikes over the 158-yr time period, and Key West has the secondhighest strike occurrence, 33. Miami, Cape Coral, Port St. Lucie, and Key West have experienced category 4 wind speeds. Only Miami has experienced a category 5 hurricane (Andrew in 1992). The Labor Day hurricane of 1935 reached category 5 strength, but at a distance greater than $100 \mathrm{~km}$ from Key West.

Looking at these results from a geographic perspective, it is seen that the "Big Bend" area of Florida (Tallahassee through Tampa, along the Gulf coast) experiences fewer hurricanes than the western panhandle and southeastern peninsula. Also, the northeast corner of the state, Jacksonville and Daytona Beach, specifically, experience 


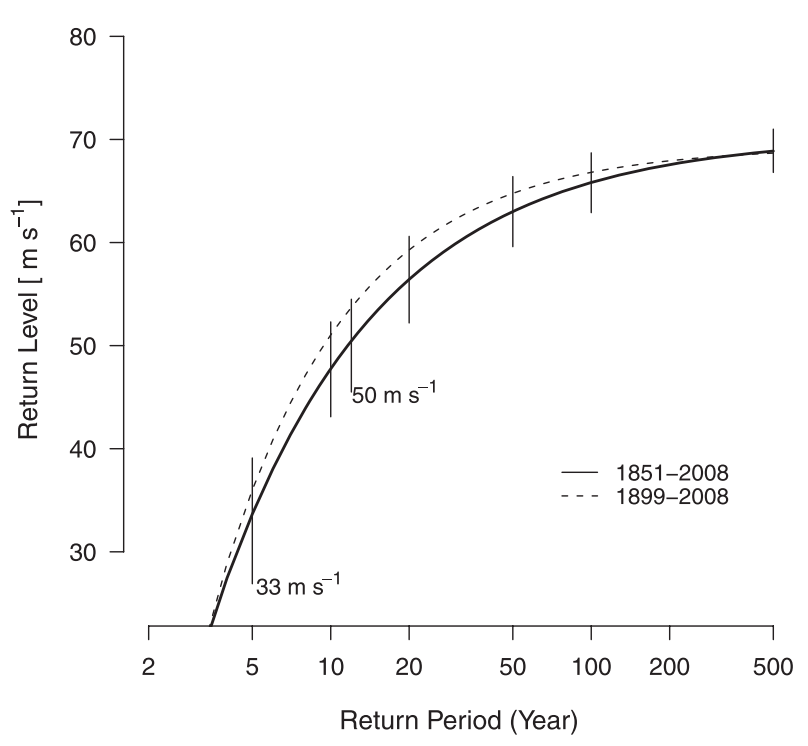

FIG. 5. Return level as a function of return period for hurricanes passing within $100 \mathrm{~km}$ of the geographic center of Miami. The solid line shows the return-level estimates from the HRC using data over the period 1851-2008. The $90 \%$ confidence intervals are shown as vertical lines. The dotted lines show the return-level estimates from the HRC using data over the period 1899-2008.

fewer hurricanes than these areas as well. The peninsula of Florida protects the Big Bend region from the strongest hurricanes approaching from the southeast, and the southeast-to-northwest orientation of the coastline north of Port St. Lucie is parallel to the tracks of hurricanes at this latitude and longitude.

Figure 6 shows return-level curves for the 100-km radial distance surrounding each city center. These curves are plotted based on their geographic locations to help visualize the spatial patterns. As expected, areas like the Big Bend and the northeast coastline show weaker wind speeds for a given return period when compared to areas like the panhandle and the southeastern coastline. The highest return levels for return periods of $500 \mathrm{yr}$ are noted in Key West, Miami, Port St. Lucie, and Cape Coral. In contrast, Tallahassee has the lowest return levels at the longest return periods. These results are tabulated in Table 2, including the $90 \%$ CI on the return-level estimates.

Table 3 shows the return-level estimates for Miami and Pensacola with their confidence intervals using data only back to 1899 . The results using the entirety of the dataset are presented alongside for comparison. The differences can be attributed to the exclusion of an additional $48 \mathrm{yr}$ of data and to data limitations. It should be noted, however, that the differences are not large relative to the range of the CI. In fact, the return-level estimates using the shorter data period fall within the $\mathrm{CI}$ of the return-level estimates from the longer period.
TABLE 1. Number of hurricanes by wind speed intervals known to have passed within a $100-\mathrm{km}$ radius of the specified city center from 1851 to 2008. Data source: NHC HURDAT. Positions and wind speeds are interpolated to 1-h intervals following the procedure outlined in Jagger and Elsner (2006).

\begin{tabular}{ccccc}
\hline \hline $\begin{array}{c}\text { Max wind } \\
\left(\mathrm{m} \mathrm{s}^{-1}\right)\end{array}$ & Miami & Orlando & Jacksonville & Tampa \\
\hline $33-42$ & 12 & 15 & 7 & 10 \\
$43-49$ & 7 & 7 & 6 & 6 \\
$50-58$ & 11 & 3 & 5 & 4 \\
$59-69$ & 4 & 0 & 0 & 0 \\
$\geq 70$ & 1 & 0 & 0 & 0 \\
& & Cape & Port & Daytona \\
& Tallahassee & Coral & St. Lucie & Beach \\
\hline $33-42$ & 8 & 4 & 10 & 13 \\
$43-49$ & 6 & 5 & 9 & 4 \\
$50-58$ & 0 & 8 & 6 & 5 \\
$59-69$ & 0 & 3 & 2 & 0 \\
$\geq 70$ & 0 & 0 & 0 & 0 \\
& & & Panama & Key \\
& Pensacola & Sarasota & City & West \\
\hline $33-42$ & 13 & 10 & 17 & 11 \\
$43-49$ & 4 & 6 & 4 & 10 \\
$50-58$ & 8 & 6 & 6 & 9 \\
$59-69$ & 0 & 0 & 0 & 3 \\
$\geq 70$ & 0 & 0 & 0 & 0 \\
\hline
\end{tabular}

Based on the HRC, a maximum wind speed can be estimated using the equation $u+(\sigma /|\xi|)$. Table 4 shows the maximum wind speed, the GPD parameters, and the threshold for each city. This wind speed can be understood as the highest possible wind speed that can be experienced within a $100-\mathrm{km}$ distance of the given city center. The list is in descending order of maximum wind speeds. At the top of the list are Port St. Lucie and Miami, with maximum wind speeds exceeding $70 \mathrm{~m} \mathrm{~s}^{-1}$, and at the bottom are Jacksonville and Tallahassee, with wind speeds of less than $55 \mathrm{~m} \mathrm{~s}^{-1}$.

The National Weather Service (NWS) also estimates hurricane wind risk for selected Florida cities. They use the HURISK model developed in Neumann (1987), which employs a Weibull distribution for tropical cyclone wind speeds and a Poisson distribution for hurricane frequency and estimates return periods at the county level. The latest output from HURISK is presented in Blake et al. (2007). The HRC estimates a return level for a given return period while the HURISK provides a return period for a given return level. Comparisons are made by converting our HRC return levels at 33 and $50 \mathrm{~m} \mathrm{~s}^{-1}$ into return periods (Table 5). The HRC estimates can be converted to provide a return period for a fixed return level via Eq. (2).

The two procedures produce similar estimates for hurricane intensities. In 4 of the 10 locations, HURISK and 


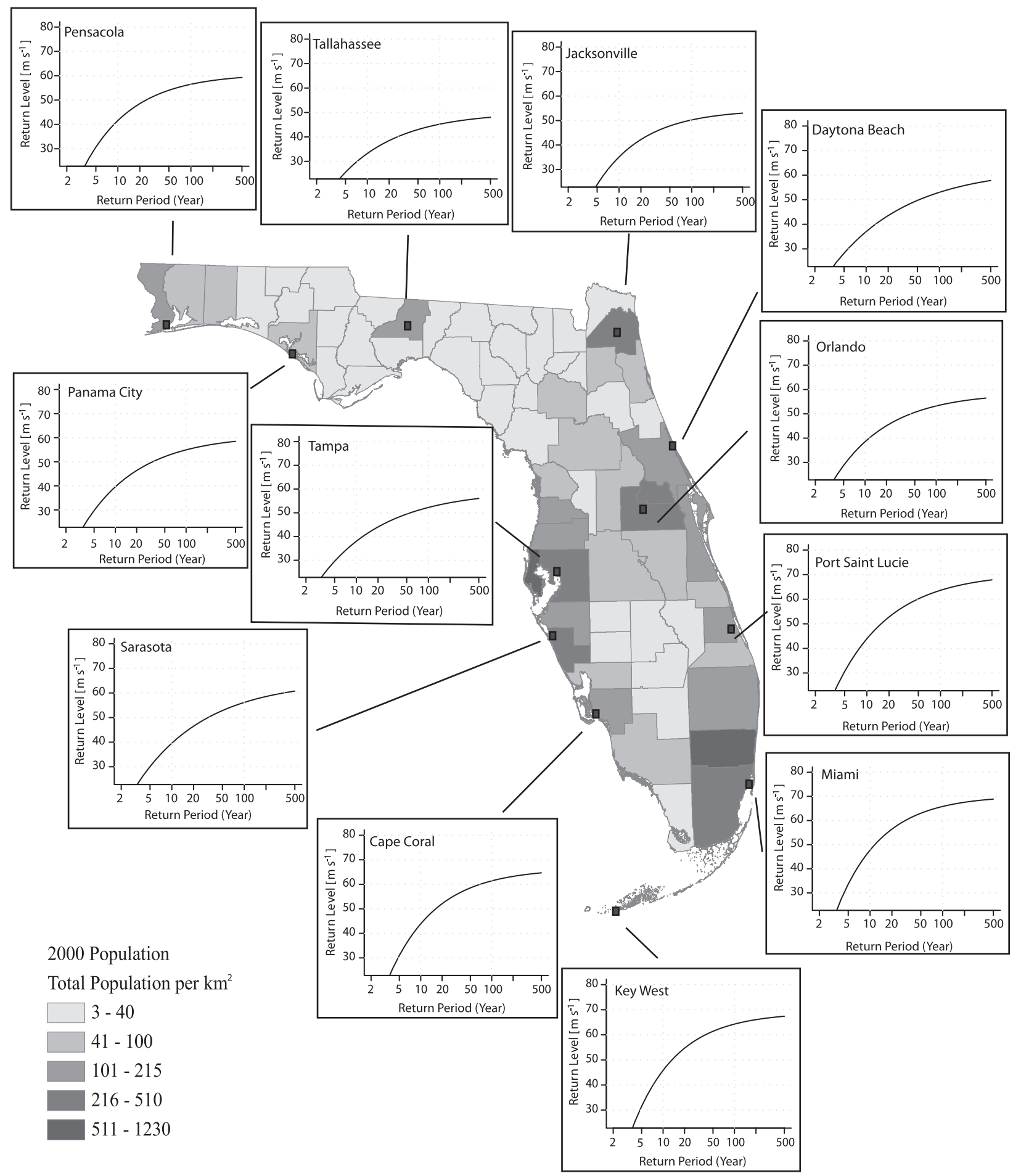

FIG. 6. Return-level curves as a function of return periods for hurricanes passing within $100 \mathrm{~km}$ of the geographic center of the specified Florida city using the HRC.

HRC give the same return period and 9 out of 10 are within 1 yr. At major hurricane intensities, the results diverge with the HRC, indicating longer return periods (lower probabilities) for the stronger storms by an average of $16 \mathrm{yr}$ (an average difference in annual probability of $6 \%$ ). The other cities (i.e., Tallahassee and Orlando) are not included in this table because the latest output from HURISK does not include a comparison. The differences 
TABLE 2. Return period for selected wind speed exceedence values. The return levels are based on the HRC presented above and include data over the period 1851-2008. The return period refers to the expected times between winds of this level blowing somewhere within a $100-\mathrm{km}$ radius of specified cities. The wind speed confidence interval in parentheses is the $90 \%$ interval.

\begin{tabular}{rcccc}
\hline \hline $\begin{array}{c}\text { Return period } \\
(\mathrm{yr})\end{array}$ & \multicolumn{4}{c}{ Hurricane wind speed $\left(\mathrm{m} \mathrm{s}^{-1}\right)$} \\
\cline { 2 - 5 } 10 & Miami & Orlando & Jacksonville & Tampa \\
20 & $47.7(43.1-52.3)$ & $38.5(34.5-42.5)$ & $35.1(32.1-38.1)$ & $38.0(34.6-41.4)$ \\
50 & $56.4(52.2-60.6)$ & $45.1(41.4-48.8)$ & $42.2(38.9-45.5)$ & $44.0(40.7-47.3)$ \\
100 & $63.0(59.6-66.4)$ & $50.6(46.9-54.3)$ & $47.8(44.5-51.1)$ & $49.5(46.3-52.7)$ \\
500 & $65.8(62.9-68.7)$ & $53.2(49.7-56.7)$ & $50.3(47.0-53.6)$ & $52.3(49.3-55.3)$ \\
& $68.9(66.8-71.0)$ & $56.5(53.2-59.8)$ & $53.0(49.7-56.3)$ & $56.1(53.4-58.8)$ \\
& Tallahassee & & & Daytona Beach \\
10 & $33.2(30.3-36.1)$ & $43.9(39.8-48.0)$ & $43.9(39.9-47.8)$ & $37.0(33.7-40.3)$ \\
20 & $38.5(35.5-41.5)$ & $52.1(48.4-55.8)$ & $52.8(49.0-56.6)$ & $43.5(40.4-46.7)$ \\
50 & $43.0(40.1-45.9)$ & $58.5(55.5-61.5)$ & $60.1(56.7-63.5)$ & $49.7(46.9-52.5)$ \\
100 & $45.2(42.4-48.1)$ & $61.4(58.9-63.9)$ & $67.6(60.5-66.7)$ & $53.0(50.6-55.4)$ \\
500 & $48.0(45.2-50.8)$ & $64.7(62.8-66.7)$ & Panama City & $57.8(55.8-59.8)$ \\
& Pensacola & Sarasota & $39.6(36.2-43.0)$ & Key West \\
\hline 10 & $41.6(38.1-45.2)$ & $39.6(35.9-43.3)$ & $46.4(42.9-49.9)$ & $45.8(41.1-50.5)$ \\
50 & $48.5(45.3-51.7)$ & $46.5(43.0-50.0)$ & $52.1(48.8-55.4)$ & $54.7(50.5-58.9)$ \\
100 & $54.0(51.3-56.7)$ & $52.8(49.7-55.9)$ & $54.9(51.1-57.3)$ & $61.4(57.8-65.0)$ \\
500 & $56.5(54.2-58.8)$ & $56.2(53.5-58.9)$ & $64.3(61.1-67.5)$ & $67.4(64.9-69.9)$ \\
\hline
\end{tabular}

in the results are attributable to differences in the wind speed distributions used by the two approaches. The Weibull distribution used in HURISK is appropriate for wind speeds at all intensities; however, by using the more frequent weaker hurricanes, the distribution tends to produce a heavy tail (Darling 1991; Jagger et al. 2001). A heavy tail is indicative of higher probabilities for the most extreme speeds. These higher probabilities translate to shorter return periods, as noted in the table for major hurricanes. Thus, while HURISK is appropriate for estimating the wind risk of typical hurricanes, it may overestimate the threat of winds in the most extreme hurricanes. For estimating the return period of the strongest hurricane wind speeds, it might be better to use a GPD, as is done in the HRC.

Return levels from the HRC are expected values representing an estimate of what magnitude hurricane we can anticipate seeing, on average, over all similar $n$-yr intervals. It is worthwhile to consider the range of maximum hurricane winds over all possible $n$-yr intervals. This is done by determining the predictive distribution of maximum winds. Figure 7 shows the predictive distribution of exceedence probabilities as a function of wind speed for given time intervals for a $100-\mathrm{km}$ radius around the city of Miami. For relatively short time intervals (e.g., $10 \mathrm{yr}$ ) the maximum wind speeds range is quite large. For instance, the $90 \%$ prediction interval for the 20 -yr maximum wind speeds ranges between 40 and $68 \mathrm{~m} \mathrm{~s}^{-1}$. But for longer time intervals, the range of wind speeds representing the $90 \%$ prediction interval is much narrower. The prediction interval is wider than the CI, as the former includes the additional variation associated with the spread of future values about the expectation.

TABLE 3. Return period for selected wind speed exceedence values for Miami and Pensacola. The return levels include data over the period 1899-2008. The wind speed confidence interval in parentheses is the $90 \%$ interval. The results using the full dataset are presented alongside for comparison.

\begin{tabular}{|c|c|c|c|c|}
\hline \multirow[b]{3}{*}{ Return period (yr) } & \multicolumn{4}{|c|}{ Hurricane wind speed $\left(\mathrm{m} \mathrm{s}^{-1}\right)$} \\
\hline & \multicolumn{2}{|c|}{$1851-2008$} & \multicolumn{2}{|c|}{ 1899-2008 } \\
\hline & Miami & Pensacola & Miami & Pensacola \\
\hline 10 & $47.7(43.1-52.3)$ & $41.6(38.1-45.2)$ & $51.0(45.5-56.5)$ & $42.9(38.0-47.8)$ \\
\hline 20 & $56.4(52.2-60.6)$ & $48.5(45.3-51.7)$ & $59.3(56.0-62.6)$ & $50.4(46.2-54.6)$ \\
\hline 50 & $63.0(59.6-66.4)$ & $54.0(51.3-56.7)$ & $64.8(62.9-66.7)$ & $55.3(52.0-58.6)$ \\
\hline 100 & $65.8(62.9-68.7)$ & $56.5(54.2-58.8)$ & $66.8(65.4-68.2)$ & $57.0(54.2-59.8)$ \\
\hline 500 & $68.9(66.8-71.0)$ & $59.3(57.4-61.2)$ & $68.7(67.8-69.6)$ & $58.6(56.3-60.9)$ \\
\hline
\end{tabular}


TABLE 4. Estimated maximum possible wind speeds. Estimates are for the strongest winds $\left(\mathrm{m} \mathrm{s}^{-1}\right)$ within $100 \mathrm{~km}$ of the city center.

\begin{tabular}{lcccc}
\hline \hline \multicolumn{1}{c}{ City } & $\begin{array}{c}\sigma \\
\left(\mathrm{m} \mathrm{s}^{-1}\right)\end{array}$ & $\xi$ & $\begin{array}{c}\text { Threshold } \\
\left(\mathrm{m} \mathrm{s}^{-1}\right)\end{array}$ & $\begin{array}{c}\text { Max wind } \\
\text { speed }\left(\mathrm{m} \mathrm{s}^{-1}\right)\end{array}$ \\
\hline Port St. Lucie & 26.5 & -0.581 & 25 & 70.6 \\
Miami & 24.7 & -0.699 & 35 & 70.3 \\
Key West & 23.7 & -0.698 & 35 & 69.0 \\
Cape Coral & 27.0 & -0.652 & 25 & 66.4 \\
Sarasota & 18.3 & -0.459 & 25 & 64.9 \\
Daytona Beach & 15.9 & -0.422 & 25 & 62.7 \\
Panama City & 14.2 & -0.547 & 35 & 61.0 \\
Pensacola & 23.2 & -0.648 & 25 & 60.8 \\
Tampa & 16.5 & -0.480 & 25 & 59.4 \\
Orlando & 13.5 & -0.569 & 35 & 58.7 \\
Jacksonville & 16.2 & -0.662 & 30 & 54.5 \\
Tallahassee & 16.3 & -0.541 & 20 & 50.1 \\
\hline
\end{tabular}

Having examined hurricane return levels across the state, we next consider whether the wind risk from hurricanes is changing over time. A stationary climate is assumed in the results presented in this section. We examine this assumption in the following section by considering evidence for changes in the frequency and intensity of hurricanes in the vicinity of Florida.

\section{Trends}

The usefulness of a return-level estimate depends to some extent on the assumption that the hurricane climate is stationary. Explicitly, the methodology of estimating the return levels presupposes that the frequency and intensity of hurricanes are not changing over time. Trends in frequency are examined using linear regression and trends in intensity are examined using quantile regression (Koenker and Bassett 1978), as was used recently in Elsner et al. (2008b). Quantile regression is an extension of linear regression applied to quantiles of the response variable. A quantile is a point taken from the inverse cumulative distribution function so that the 0.5 quantile is the value such that $50 \%$ of the values are less than the value.

Because of the rarity of hurricanes affecting any small area, the uncertainty on a trend estimate will be large. So, here, we examine the data for trends in the frequency and intensity of hurricanes falling within a $1000-\mathrm{km}$ radius of $26^{\circ} \mathrm{N}$ and $82^{\circ} \mathrm{W}$ off the southwest coast (Fig. 8). This is the area described by Hamid et al. (2009) in an attempt to identify storms that could conceivably impact Florida. The Florida Commission on Hurricane Loss Projection Methodology (FCHLPM), created during the 1995 Florida legislative session to evaluate hurricane risk models, advises modelers to consider hurricanes in this area as a potential threat to Florida. This is done for the
TABLE 5. Return periods (yr) from HURISK and HRC are shown for selected FL cities. Hurricanes are denoted by $\mathrm{H}$ and major hurricanes are denoted by MH. St. Lucie County is included to show a comparison between the return periods for Fort Pierce (HURISK) and Port St. Lucie (HRC). Lee County is included to show a comparison between Fort Myers (HURISK) and Cape Coral (HRC). Differ is the return period from HURISK minus the return period from HRC.

\begin{tabular}{|c|c|c|c|c|c|c|}
\hline & \multicolumn{6}{|c|}{ Return period (yr) } \\
\hline & \multicolumn{2}{|c|}{ HURISK } & \multicolumn{2}{|c|}{$\mathrm{HRC}$} & \multicolumn{2}{|c|}{ Differ } \\
\hline & $\mathrm{H}$ & MH & $\mathrm{H}$ & MH & $\mathrm{H}$ & $\mathrm{MH}$ \\
\hline Pensacola & 7 & 17 & 6 & 24 & 1 & -7 \\
\hline Panama City & 6 & 17 & 6 & 34 & 0 & -17 \\
\hline Tampa & 6 & 23 & 7 & 56 & -1 & -33 \\
\hline Sarasota & 6 & 19 & 6 & 32 & 0 & -13 \\
\hline Key West & 5 & 12 & 5 & 13 & 0 & -1 \\
\hline Miami & 4 & 9 & 5 & 12 & -1 & -3 \\
\hline Daytona Beach & 8 & 31 & 7 & 52 & 1 & -21 \\
\hline Jacksonville & 9 & 28 & 9 & 92 & 0 & -64 \\
\hline St. Lucie County & 7 & 17 & 5 & 16 & 2 & 1 \\
\hline Lee County & 6 & 15 & 5 & 16 & 1 & -1 \\
\hline
\end{tabular}

purposes of comparing different risk models used by the insurance industry (Hamid et al. 2009; Jagger and Elsner 2009) by using a common set of hurricanes. The area encompasses cyclones that affect the panhandle, west, and northeast coasts of Florida, as well as cyclones that approach south Florida from the vicinity of Cuba and the Bahamas. We use this location and data back to 1899 because, according to Landsea et al. (2004), the turn of the twentieth century is the appropriate place to start for reliable landfall records for the United States. The dataset includes 162 individual hurricanes over the period 1899-2008, inclusive.

The frequency and intensity of hurricanes as a function of year are shown in Fig. 9. There is no upward or downward trend in the occurrence rates of hurricanes or major hurricanes in the vicinity of Florida, but there does appear to be a low-frequency fluctuation that matches variations in sea surface temperatures (Saunders and Harris 1997; Landsea et al. 1999; Wang et al. 2008).

The strongest hurricanes appear to be getting stronger. The trend lines represent the 50th and 90th percentile regressions of maximum wind speed vs year. The maximum wind speed is the largest wind speed for each hurricane within the Florida threat area. The upward trend at the median is $7 \mathrm{~m} \mathrm{~s}^{-1}$ century $^{-1}$ with a standard error of $3 \mathrm{~m} \mathrm{~s}^{-1}$ century $^{-1}$. The upward trend at the 90th percentile is $13 \mathrm{~m} \mathrm{~s}^{-1}$ century ${ }^{-1}$ with a standard error of $6 \mathrm{~m} \mathrm{~s}^{-1}$ century $^{-1}$. If only the years from 1950 onward are included, the upward trend increases to $21 \mathrm{~m} \mathrm{~s}^{-1}$ century $^{-1}$ with a standard error of $20 \mathrm{~m} \mathrm{~s}^{-1}$ century $^{-1}$. The trends assume the data are uniformly reliable over the period of record. This assumption may not hold up under closer 


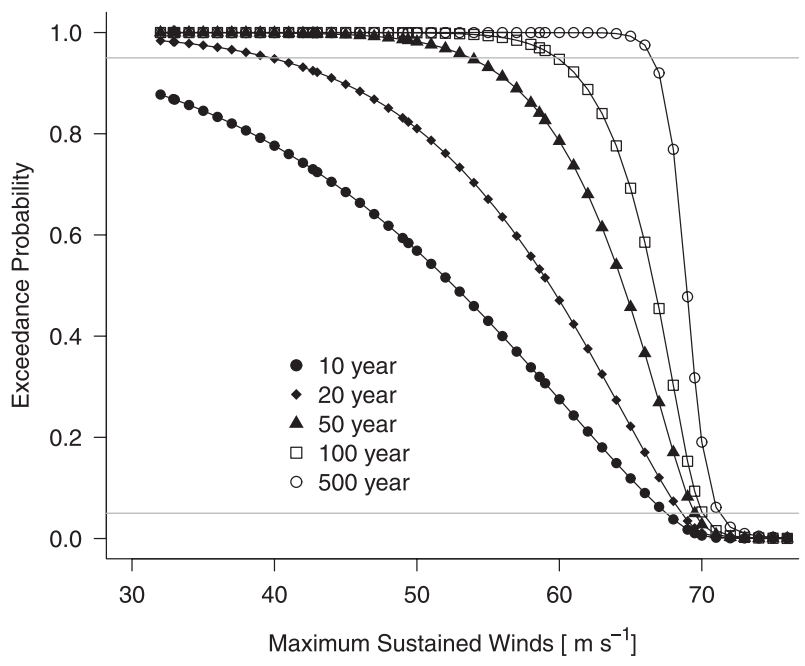

FIG. 7. The posterior exceedance probabilities as a function of wind speed over given time intervals for a $100-\mathrm{km}$ radius around the city of Miami. Horizontal lines are drawn at probabilities of 0.05 and 0.95 . For a given $n$-yr time interval, the range of wind speeds at these two probabilities is the $90 \%$ prediction interval.

scrutiny of the influence that changes in measuring techniques and sampling rates have on the wind estimates. These results suggest that our return levels might be too low for estimates of future hurricane wind risk.

To better understand the upward trends in hurricane wind speeds, we estimate hourly intensification rates along the hurricane tracks within the Florida threat area. The intensification is the time change of the maximum hurricane wind speed. We divide the dataset into values that are above zero, indicating hurricane strengthening, and values below zero, which indicate hurricane weakening. We then take the maximum value of the strengthening (intensification) along the track of each hurricane within the threat area to obtain one intensification value per hurricane. We multiply these values by 24 to express the maximum hourly intensification in terms of a daily rate and plot them as a function of year in Fig. 10. The 10th, 50th, and 90th percentiles are analyzed for trends using quantile regression. Significant upward trends in intensification rates are observed. The greater intensification rates of late do not necessarily imply more intense hurricanes at the point of landfall. These upward trends are consistent with the increasing ocean heat content noted over the Gulf of Mexico and the western Caribbean (Carton and Santorelli 2008).

\section{Summary and conclusions}

Hurricanes top the list of most destructive and costly natural disasters in the United States. The state of Florida, especially, has experienced over $\$ 450$ billion

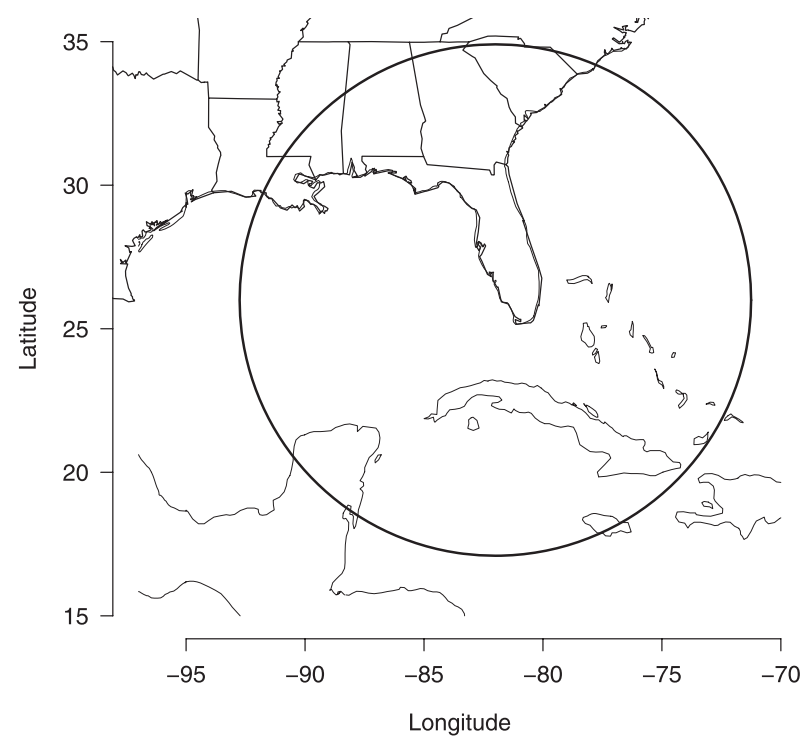

FIG. 8. The threat area around FL is shown with a black circle. This area is described by Hamid et al. (2009) as a 1000-km radius of a location $\left(26^{\circ} \mathrm{N}\right.$ and $\left.82^{\circ} \mathrm{W}\right)$ off the southwest FL coast.

in damages from these events since the early twentieth century (Malmstadt et al. 2009). Estimates of return levels for the strongest hurricane winds provide emergency planners and the insurance industry information by which to make decisions. Here, we used standard hurricane data to model wind speed return levels for the strongest hurricanes passing within a $100-\mathrm{km}$ radius of 12 cities in Florida. The model is based on the GPD with parameters estimated locally by borrowing information on the frequency and intensity of hurricanes over larger regions.

Not unexpectedly, it was found that the extreme wind risk from hurricanes varies across the state. Areas in the northeast, such as Jacksonville, and in the Big Bend, between Tampa and Tallahassee, have longer return periods for a given strong wind speed compared with areas such as Miami in the southeast and Pensacola in the panhandle. Thus, the annual threat of a catastrophic hurricane event is highest in the southeast and the western panhandle of the state.

The sensitivity of the return-level estimates was examined by limiting the input data to the more recent years (1899 and after). The return levels are quite similar, indicating that, despite the greater level of uncertainty in the records prior to 1899 , the frequency and intensity of the strongest hurricanes are consistent over the longer period of record.

An implicit assumption underlying the results is that of stationarity, which was examined by trend analysis on hurricane frequency and intensity in the vicinity of Florida. We found that the frequency of hurricanes and major 

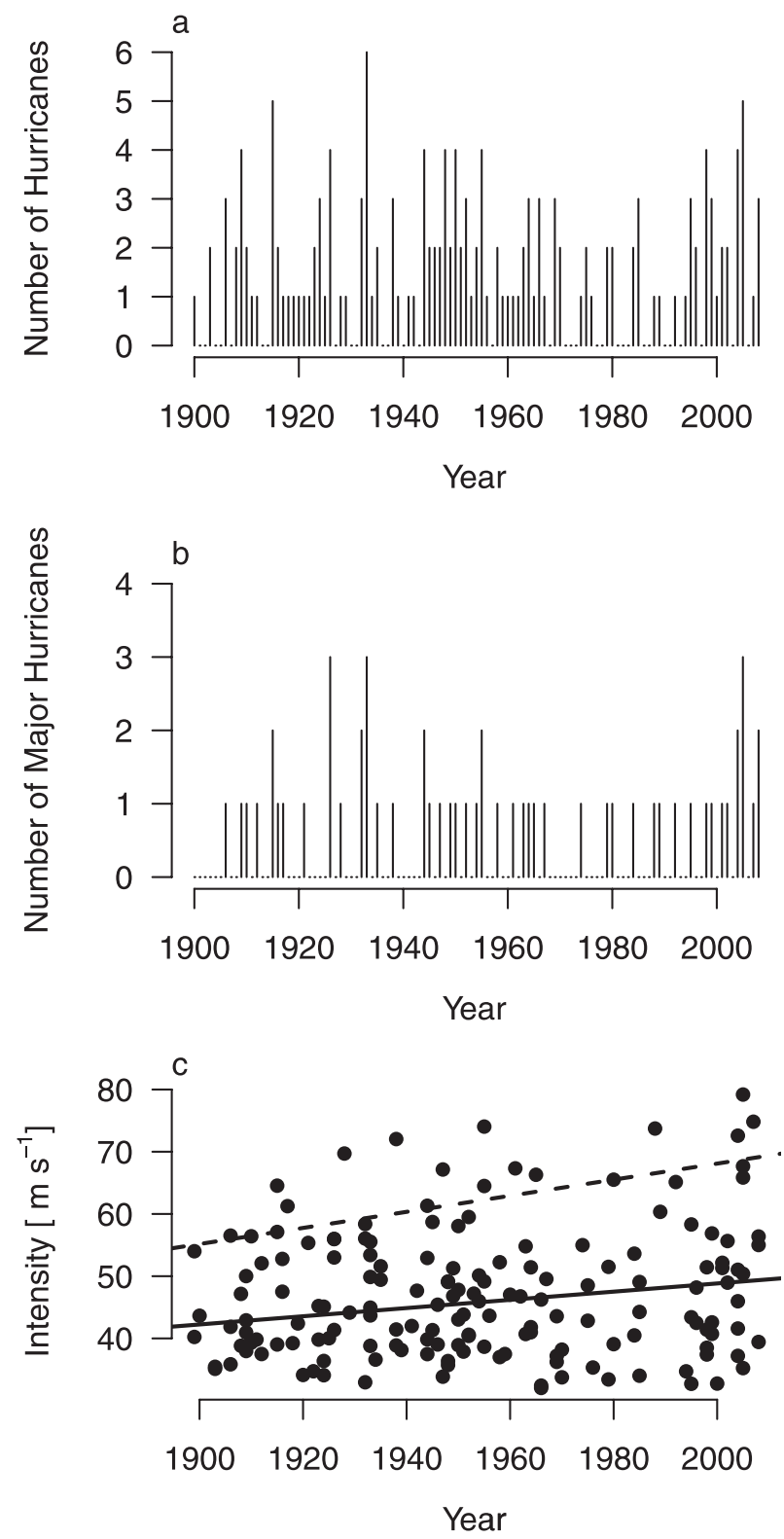

FIG. 9. Florida area frequency of (a) hurricanes and (b) major hurricanes (category 3 and above) as functions of time. (c) Intensity (maximum sustained wind speed) of hurricanes as a function of time with trend lines shown for the 50th and 90th percentiles.

hurricanes is rather constant through time. However, there is evidence of upward trends in the intensity of the strongest hurricanes. In fact, at the 90th percentile the upward trend is estimated at $13 \pm 6 \mathrm{~m} \mathrm{~s}^{-1}$ century ${ }^{-1}$. This is occurring in conjunction with statistically significant upward trends in the intensification rates and is consistent with rising ocean heat content over the Gulf of Mexico.

The study can be extended by applying the approach across space and mapping the HRC parameters as a

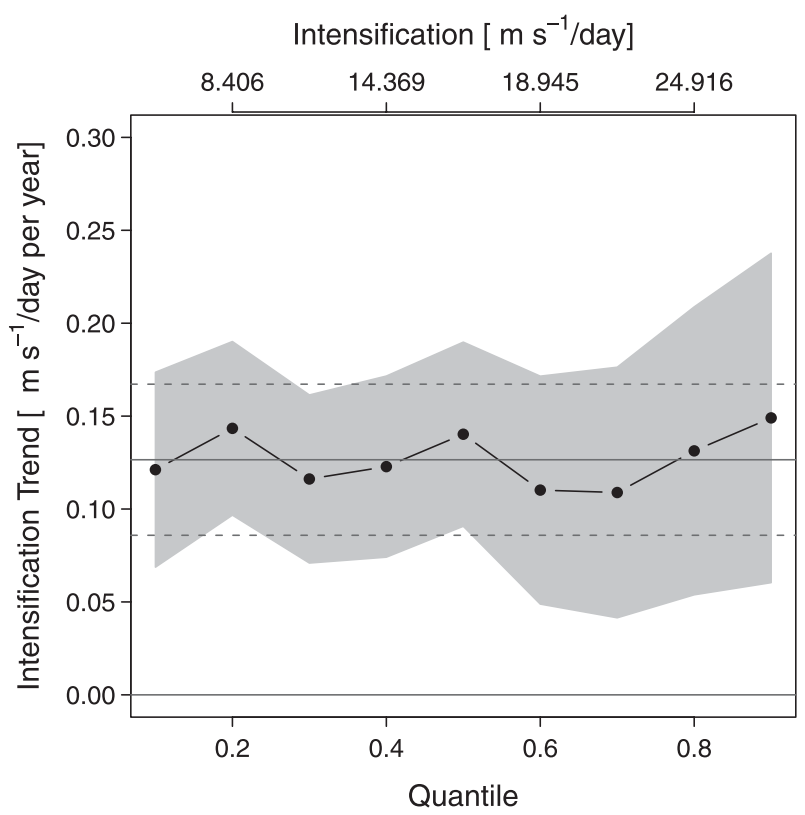

FIG. 10. Trends in the maximum intensification rate of hurricanes as a function of quantile, from the 10th to the 90th percentile in increments of 10 . The maximum intensification rate is calculated as the rate of change between hourly observations for each hurricane that passed within a $1000-\mathrm{km}$ radius of the specified location. Trends are estimated coefficients from quantile regression $\left(\mathrm{m} \mathrm{s}^{-1} \mathrm{~h}^{-1} \mathrm{yr}^{-1}\right)$. The point-wise $90 \%$ confidence band is shown in gray. The solid line is the trend from a least squares regression of the rate of intensification as a function of year, and the dashed lines delineate the $90 \%$ confidence band about this trend.

function of location. In this way, the results from the HRC can be used without the need to access the internal procedure. Spatial variations in the model parameters might provide new insights into hurricane behavior.

The study can be improved by determining a method to adjust the return-level estimates to reflect the upward trends in hurricane intensity. One possibility is to model hurricane frequency as a function of time or sea temperature and integrate the modeled frequencies over, say, $100 \mathrm{yr}$. The ratio of the modeled frequency to the historical frequency could provide a scaling factor for the rate parameter of the Poisson distribution in the HRC. A similar adjustment could be made for the parameters of the generalized Pareto distribution.

Acknowledgments. We thank Robert Lund and the other reviewers of this paper for their suggestions and comments. All computations were completed using the $\mathrm{R}$ statistical package with thanks given to the $\mathrm{R}$ Development Core Team and the quantile regression package quantreg ( $\mathrm{R}$ package version 4.36; information online at http://www.r-project.org) with special thanks given to Roger Koenker. The work was supported by the U.S. National Science Foundation (ATM-0738172), the Risk 
Prediction Initiative of the Bermuda Institute for Ocean Studies (RPI06-3-001), and the Florida Catastrophic Storm Risk Management Center.

\section{REFERENCES}

Bin, O., J. Kruse, and C. Landry, 2008: Flood hazards, insurance rates, and amenities: Evidence from the coastal housing market. J. Risk Insur., 75, 63-82.

Blake, E., E. Rappaport, and C. Landsea, 2007: The deadliest, costliest, and most intense United States tropical cyclones from 1851 to 2006 (and other frequently requested hurricane facts). National Weather Service Tech. Memo. NWS TPC-5, 45 pp.

Carton, J., and A. Santorelli, 2008: Global upper ocean heat content as viewed in nine analyses. J. Climate, 21, 6015-6035.

Chu, P., and J. Wang, 1998: Modeling return periods of tropical cyclone intensities in the vicinity of Hawaii. J. Appl. Meteor., 37, 951-960.

Coles, S., 2001: An Introduction to Statistical Modeling of Extreme Values. Springer, 208 pp.

Darling, R., 1991: Estimating probabilities of hurricane wind speeds using a large-scale empirical model. J. Climate, 4, 1035-1046.

Davison, A., and R. Smith, 1990: Models for exceedences over high thresholds. J. Roy. Stat. Soc., 52B, 393-442.

Elsner, J., T. Jagger, K.-b. Liu, 2008a: Comparison of hurricane return levels using historical and geological records. J. Appl. Meteor. Climatol., 47, 368-374.

— the strongest tropical cyclones. Nature, 455, 92-95.

Emanuel, K., S. Ravela, E. Vivant, and C. Risi, 2006: A statistical deterministic approach to hurricane risk assessment. Bull. Amer. Meteor. Soc., 87, 299-314.

Fernandez-Partagas, J., and H. Diaz, 1996: Atlantic hurricanes in the second half of the nineteenth century. Bull. Amer. Meteor. Soc., 77, 2899-2906.

Hamid, S., B. Kibria, S. Gulati, M. Powell, B. Annane, S. Cocke, J. Pinelli, and C. Chen, 2009: Predicting losses of residential structures in the state of Florida by the public hurricane loss evaluation model. Stat. Method., 5, 552-573.

Heckert, N., E. Simiu, and T. Whalen, 1998: Estimates of hurricane wind speeds by peaks over threshold method. J. Struct. Eng., 124, 445-449.

Jagger, T., and J. Elsner, 2006: Climatology models for extreme hurricane winds in the United States. J. Climate, 19, 32203236.

_ quantile regression. Int. J. Climatol., 29, 1351-1361.

$\ldots, \ldots$, and X. Niu, 2001: A dynamic probability model of hurricane winds in coastal counties of the United States. J. Appl. Meteor., 40, 853-863.

Koenker, R., and G. Bassett, 1978: Regression quantiles. Econometrica, 46, 33-50.

Landsea, C., R. Pielke Jr., A. Mestas-Nunez, and J. Knaff, 1999: Atlantic basin hurricanes: Indices of climatic changes. Climatic Change, 42, 89-129.

_ , and Coauthors, 2004: The Atlantic hurricane database reanalysis project: Documentation for the 1851-1910 alterations and additions to the HURDAT database. Hurricanes and Typhoons: Past, Present, and Future, R. Murnane and K. B. Liu, Eds., Columbia University Press, 177-221.

Malmstadt, J., K. Scheitlin, and J. Elsner, 2009: Florida hurricanes and damage costs. Southeast. Geogr., 49, 108-131.

Neumann, C., 1987: The National Hurricane Center risk analysis program (HURISK). National Hurrican Center Tech. Memo. NWS NHC 38, 59 pp.

Parisi, F., and R. Lund, 2008: Return periods of continental U.S. hurricanes. J. Climate, 21, 403-410.

Saunders, M., and A. Harris, 1997: Statistical evidence link exceptional 1995 Atlantic hurricane season to record sea warming. Geophys. Res. Lett., 24, 1255-1258.

Wang, C., S. Lee, and D. Enfield, 2008: Atlantic Warm Pool acting as a link between Atlantic Multidecadal Oscillation and Atlantic tropical cyclone activity. Geochem. Geophys. Geosyst., 9, Q05V03, doi:10.1029/2007GC001809. 